\title{
Screening of Two Ocimum tenuiflorum L. (Lamiaceae) Morphotypes for their Morphological Characters, Essential Oil Composition and Fruit Fly Attractant Ability
}

\author{
R.M. Dharmadasa ${ }^{1,}$, D.A.S. Siriwardhane ${ }^{1}$, K. Samarasinghe, S.H.C.S. Rangana ${ }^{1}$, L. Nugaliyadda ${ }^{2}$, \\ Indika Gunawardane ${ }^{3}$, A.M.L. Aththanayake ${ }^{1}$ \\ ${ }^{1}$ Industrial Technology Institute, 363, Bauddhaloka Mawatha, Colombo 7, Sri Lanka \\ ${ }^{2}$ Faculty of Agriculture, University of Ruhuna, Kamburupitiya, Sri Lanka \\ ${ }^{3}$ CIC Holdings, Colombo -2, Sri Lanka \\ *Corresponding author: dharmadasarm@gmail.com
}

Received December 14, 2014; Revised December 24, 2014; Accepted January 05, 2015

\begin{abstract}
Bactrocera dorsalis (Hendel) (Diptera: Tephritidae) is the destructive pest of over 300 cultivated and wild fruits all over the world. Present study describes the morphology, essential oil content and composition and bioassay on fruit fly attractant ability of essential oil of two Ocimum tenuiflorum morphotypes ( $\mathrm{MT}_{1}$ purple and $\mathrm{MT}_{2}$ purple-green) grown in Sri Lanka. Four months old, $O$. tenuiflorum aerial parts were hydro-distilled for $4 \mathrm{~h}$. GC-MS analysis of essential oils and bio-assay for $B$. dorsalis attractant ability was performed using previously established methodologies. The yield of the essential oils of $O$. tenuiflorum $\mathrm{MT}_{1}$ and $\mathrm{MT}_{2}$ were $1.51 \pm 0.02 \%$ and $1.45 \pm 0.01 \%$ $(\mathrm{v} / \mathrm{w})$, respectively. Eighteen compounds were identified, which encountered over $97 \%$ of the oil constituents. The main constituents found in the oil of $\mathrm{MT}_{1}$ were methyl eugenol $(72.50 \pm 1.03 \%)$ followed by $\beta$-caryophyllene $(17.53 \pm 2.0 \%)$, germacrene D $(1.55 \pm 0.10 \%)$, $\beta$-elemene $(2.46 \pm 0.17 \%)$, while methyl eugenol $(64.23 \pm 2.43 \%)$, $\beta$ caryophyllene (13.29 $\pm 2.18 \%)$, $\beta$-elemene (6.94 $\pm 1.41 \%)$, germacrene $\mathrm{D}(2.47 \pm 0.96 \%)$, were from extracted from $\mathrm{MT}_{2}$. Bioassays conducted on essential oils of $\mathrm{MT}_{1}, \mathrm{MT}_{2}$ and purified Methyl Eugenol demonstrated that the $B$. dorsalis attractant ability of essential oil MT1 (106 \pm 8.1$)$, MT2 104 \pm 2 and commercial Methyl Eugenol (111 \pm 8.5$)$ was not significantly different during the first week of the experiment. Results of our study open an avenue for use of essential oil of Ocimum tenuiflorum as potential natural para pheromone source for fruit fly control and monitoring in fruit industry in Sri Lanka.
\end{abstract}

Keywords: Ocimum tenuiflorum, Lamiaceae, fruit fly, methyl eugenol, parapheromone, essential oil

Cite This Article: R.M. Dharmadasa, D.A.S. Siriwardhane ${ }^{1}$, K. Samarasinghe, S.H.C.S. Rangana ${ }^{1}$, L. Nugaliyadda, Indika Gunawardane, and A.M.L. Aththanayake, "Screening of Two Ocimum tenuiflorum L. (Lamiaceae) Morphotypes for their Morphological Characters, Essential Oil Composition and Fruit Fly Attractant Ability.” World Journal of Agricultural Research, vol. 3, no. 1 (2015): 1-4. doi: 10.12691/wjar-3-1-1.

\section{Introduction}

Bactrocera dorsalis (Hendel) (Diptera: Tephritidae) is the serious destructive pest of over 300 cultivated and wild fruits and vegetables including Annona (sugar apple), avocado, banana, citrus, coffee, guava, mango, papaya, passion fruit, peppers and tomato. This pest will apparently breed in all fleshy fruits [1]. The damage by oriental fruit fly is an impediment for establishment of commercial orchards of fruits than can be grown in Hawaii [2]. A number of methods to control these important pests of fruits, such as chemical control [3], cultural control [4], combinations of insecticides and plant products [5] and culture filtrates of fungi [6] have also been tried out. However, chemical control methods for fruit fly control were unsuccessful $[7,8]$. The substance that contain single component (males lure) called parapheromone is only effective to capture male fruit fly. Meanwhile, pheromone traps with synthesized methyl eugenol have been used to eliminate the fruit fly damage by many people $[9,10,11,12]$. Moreover, this technique has been successfully practiced to monitor the fruit fly populations in India and Pakistan [13,14]. However, commercial synthesizing process of methyl eugenol is risky and expensive (US\$ 200/kg) and importation of required chemicals for the methylation process is difficult due to its high toxic nature. Therefore, development of an effective, plant based insect attractant, at an affordable price, is urgently needed.

Ocimum tenuiflorum L. (Lamiaccae) is one of the most famous, perennial herbs native to Africa, India and Asia, cultivated in temperate climate throughout the world with about 150 varieties. Interestingly essential oil of Ocimum 
tenuiflorum contains $0.7 \%$ essential oils, of which $20-50 \%$ is methyl eugenol [15]. In the present study we identified chemical composition of essential oils of two morphotypes of Ocimum tenuiflorum and compared fruit fly attractant ability of two $O$. sanctum morphotypes.

\section{Materials and Methods}

\subsection{Test Plants of Ocimum Tenuiflorum}

Four-month-old plants of two morpho-types (MT) of Ocimum tenuiflorum grown under same environmental conditions at the Institutional premises (6.54'13900 N, 79.52 '12492 E) were used for the extraction of essential oil. Prominent morphological characters of the above two morpho-types were recorded and herbarium specimens of the same ( $\mathrm{MT}_{1}$ as HTS 19 and $\mathrm{MT}_{2}$ as HTS 20) were deposited at institutional herbarium.

\subsection{Extraction of Essential Oil}

Ten plants each of Ocimum tenuiflorum MT1 and MT2 were harvested at flowering and the leaves were hydrodistilled in a Clevenger-type apparatus for 5h. The extracted volatile oils were dried over anhydrous sodium sulphate and stored in sealed vials at $4^{\circ} \mathrm{C}$ until analysis. The yield of the oils was calculated based on dry weight of plant materials.

\subsection{Gas Chromatography-Mass Spectrometry (GC-MS) Analysis}

GC-MS analysis was carried out on a Hewlett-Packard 6890 Gas Chromatograph fitted with a fused silica HP5MS capillary column $(30 \mathrm{~m} \times 0.25 \mathrm{~mm}$; film thickness $0.25 \mu \mathrm{m})$. The oven temperature was programmed from 60 - $280^{\circ} \mathrm{C}$ at $4^{\circ} \mathrm{C} / \mathrm{min}$. Helium was used as carrier gas at a flow rate of $2 \mathrm{~mL} / \mathrm{min}$. The gas chromatograph was coupled to a Hewlett-Packard 6890 mass selective detector. The MS operating parameters were ionization voltage, $70 \mathrm{eV}$; and ion source temperature, $200^{\circ} \mathrm{C}$.

\subsection{Bioassay of Essential Oil}

Bioassays were conducted in home-gardens, where $B$. dorsalis infestation was predominant in mango, and other fruit crops (guava, avocado, and banana) Pheromone traps used to catch the fruit flies were prepared from roundshaped hollow plastic containers $(20 \mathrm{~cm}$ length $\mathrm{x} 10 \mathrm{~cm}$ diameter). The lid on each side of the container had a pipe fixed in its center to allow the flies to enter into the trap. The inner diameter of each pipe was $1 \mathrm{~cm}$ and it was protruded into the plastic container for a length of $5 \mathrm{~cm}$. In each trap $0.1 \mathrm{~mL}$ of essential oil was injected into a cotton wick that was suspended in the center of the trap with a wire and the same amount of methyl eugenol was used as a control. The traps were placed at a spacing of $50 \mathrm{~m}$ each in the home garden and they were fixed at a height of 1.5 $\mathrm{m}$ above ground. Experiment was conducted from January to August 2013. Attracted fruit flies for each trap containing $\mathrm{ME}$, essential oil of $\mathrm{MT}_{1}$ and $\mathrm{MT}_{2}$ were identified with the help of an Entomologist for the correct species. The data on number of fruit flies attracted to each treatment was counted and tabulated.

\subsection{Statistical Analysis}

The data were analyzed using the analysis of variance (ANOVA) and the means were compared by using the Tukey's Multiple Range Tests $(\mathrm{P}<0.05)$ of SPSS statistical package 11.5 version.

\section{Results and Discussion}

Present study compares the morphological, essentiail oil content, essential oil composition, fruit fly attractant ability of two methyl eugenol rich Ocimum tenuiflorum morphotypes ( $\mathrm{MT}_{1}$ purple and $\mathrm{MT}_{2}$ purple-green) grown in Sri Lanka. Since both morphotypes were grown in same soil and climatic conditions, as well as same aged plants, the observed results reflected the true morphological, phytochemical and insect attractant ability of both morphotypes.

\subsection{Morphological Variations of Two Morpho-types of Ocimum Tenuiflorum}

Out of the 35 morphological characters recorded, 11 were identified as distinguishable features of $\mathrm{MT}_{1}$ (Purple) and $\mathrm{MT}_{2}$ (Purple-green) (Table 1). Leaf and stem colour, leaf margin, leaf apex and leaf width can be used to differentiate the two morphotypes.

Table 1. Morphological characters of the two Ocimum tenuiflorum morphotypes used for the extraction of essential oils

\begin{tabular}{|c|c|c|}
\hline Character & MT1 (Purple) & $\begin{array}{c}\text { MT2 (Purple } \\
\text { Green) }\end{array}$ \\
\hline Plant habit & $\begin{array}{c}\text { Erect, much } \\
\text { branched }\end{array}$ & Intermediate \\
\hline Plant height & $30-75 \mathrm{~cm}$ & $40-60 \mathrm{~cm}$ \\
\hline Leaf margin & Serrate & Undulate \\
\hline Leaf shape & Elliptic-Oblong & Subulate \\
\hline Leaf apex & Acute & Cupsidate \\
\hline $\begin{array}{c}\text { Colour of the dorsal } \\
\text { surface }\end{array}$ & Dark Purple & Purplish Green \\
\hline $\begin{array}{c}\text { Colour of the ventral } \\
\text { surface }\end{array}$ & Purplish Green & Green \\
\hline Leaf length & $3.5-4 \mathrm{~cm}$ & $3.1-3.5 \mathrm{~cm}$ \\
\hline Leaf width & $2.5-3 \mathrm{~cm}$ & $1.8-2.2 \mathrm{~cm}$ \\
\hline Length of the petiole & $1.3-2.5 \mathrm{~cm}$ & $1.0-2.0 \mathrm{~cm}$ \\
\hline Internodal space & $2.5-4.0 \mathrm{~cm}$ & $2.0-2.5 \mathrm{~cm}$ \\
\hline
\end{tabular}

\subsection{Essential Oils of Two Morphotypes of Ocimum Tenuiflorum}

Chemical composition of essential oil mainly depend on soil and climatic conditions of the location, growing season and maturity stages [16]. However, plants subjected to present study were cultivated at the same location under same soil and climatic conditions and harvested at the same age. Therefore, variability of essential oil composition could be considered as variation between two morphotypes. The yield of the essential oils obtained from aerial parts of Ocimum tenuiflorum MT1 and $\mathrm{MT}_{2}$ were $1.51 \pm 0.02 \%(\mathrm{v} / \mathrm{w})$ and $1.45 \pm 0.01 \%(\mathrm{v} / \mathrm{w})$, respectively.

The GC-MS analysis of the oils identified more than $97 \%$ of the oil constituents (Table 2). As demonstrated in Table 2, the main constituents present in the oil of both Ocimum tenuiflorum morphotypes was methyl eugenol $\left(\mathrm{MT}_{1-}(72.50 \pm 1.03 \%)\right.$ and $\mathrm{MT}_{2-}$ 64.23 \pm 2.43$)$ followed by, $\beta$-caryophyllene $\quad(17.53 \%), \quad \beta$-elemene $\quad(2.46 \%)$. 
Correspondingly, oil of Ocimum tenuiflorum morphotype -2 $\left(\mathrm{MT}_{2}\right)$ contained methyl eugenol (64.23\%), $\beta$ caryophyllene $(13.29 \%)$, $\beta$-elemene $(6.94 \%)$ as major components.

Our results clearly demonstrated the presence of more than $60 \%$ of methyl eugenol in both morphotypes and it was significantly higher in $\mathrm{MT}_{1}(\mathrm{p}>0.05)$. Moreover, all 13 constituents identified were common to both morphotypes tested. This is quite acceptable as both morphotypes belonged to the same species. Further, all the constituents we have identified have been reported by previous studies and methyl eugenol have been identified as major constituent in Ocimum species grown in India, and Thailand [17]. Moreover, varietal methyl eugenol content, of Ocimum tenuiflorum grown in Thailand and Indian conditions exhibited the higher content of Methyl eugenol [18]. Therefore, the findings on essential oil content and composition in the present study are in agreement with previous studies conducted elsewhere.

Table 2. Composition of the essential oils of Ocimum tenuiflorum $\mathrm{MT}_{1}$ (purple) and $\mathrm{MT}_{2}$ (purple green)

\begin{tabular}{|c|c|c|}
\hline \multirow{2}{*}{ Compound } & \multicolumn{2}{|c|}{ Compound percentage (\%) } \\
\cline { 2 - 3 } & $\mathrm{MT}_{1}$ & $\mathrm{MT}_{2}$ \\
\hline$\alpha$-pinene & $0.16 \pm 0.02$ & $0.77 \pm 0.11$ \\
\hline Camphene & $0.13 \pm 0.01$ & $0.74 \pm 0.03$ \\
\hline Sabinene & $0.04 \pm 0.01$ & $0.11 \pm 0.01$ \\
\hline$\beta$-pinene & $0.08 \pm 0.01$ & $0.43 \pm 0.01$ \\
\hline 1-Limonene & $0.04 \pm 0.01$ & $0.2 \pm 0.00$ \\
\hline$\gamma$-Terpinene & $0.04 \pm 0.01$ & $0.03 \pm 0.00$ \\
\hline$\alpha$-Terpinolene & $0.04 \pm 0.01$ & $0.03 \pm 0.00$ \\
\hline Camphor & $0.04 \pm 0.01$ & $0.14 \pm 0.01$ \\
\hline Eugenol & $0.17 \pm 0.02$ & $<0.03 \pm 0.00$ \\
\hline$\beta$ - elemene & $2.46 \pm 0.17$ & $6.94 \pm 1.41$ \\
\hline$\beta$-Caryophyllin & $17.53 \pm 2.00$ & $13.29 \pm 2.18$ \\
\hline Methyl eugenol & $72.50 \pm 1.03$ & $64.23 \pm 2.43$ \\
\hline$\alpha$-humulene & $1.0 \pm 00$ & $1.08 \pm 0.02$ \\
\hline Germacrene D & $1.55 \pm 0.10$ & $5.58 \pm 1.21$ \\
\hline$\beta$-cubebene & $2.55 \pm 1.46$ & $2.47 \pm 0.96$ \\
\hline$\gamma$-Cadinene & $0.2 \pm 0.0$ & $<0.03 \pm 0.01$ \\
\hline$\gamma$-murolene & $0.04 \pm 0.10$ & $0.16 \pm 0.01$ \\
\hline$\alpha$--cadinene & $0.71 \pm 0.10$ & $0.87 \pm 0.01$ \\
\hline
\end{tabular}

\subsection{Bioassay of Essential Oil on Fruit Fly}

Methyl eugenol (4-allyl-1, 2-dimethoxybenzenecarboxylate, ME), is the most effective naturally occurring male-fruit fly attractant and hence widely used in population estimation, and as detection, monitoring, and control of male fruit flies $[18,19,20]$. The highest methyl eugenol senstivity of fruit fly species was observed for $B$. dorsalis, followed by B. papayae and B. carambolae [20].

Once methyl eugenol rich essential oils are identified, they should be bio assayed against fruit fly species in order to ensure the effectiveness of the essential oils. Therefore, in the present study we have bioassayed essential oils of two mophotypes with a positive control (Commercial methyl eugenol) as described in section 2.4. The number of fruit flies attracted to essential oil from $\mathrm{MT}_{1}$ and $\mathrm{MT}_{2}$ were found to be similar to those attracted to Methyl Eugenol from $1^{\text {st }}$ to $4^{\text {th }}$ week of field exposure (Table 3). The fruit flies attracted to traps went down by $40 \%$ in 4 weeks after exposure in all treatments tested. Therefore, the tested morphotypes of Ocimum tenuiflorum can be considered as sources for commercial extraction of para-pheromone. These results are in agreement with Llopis et al., who reported the attraction of Bactrocera oleae and Ceratitis capitata, to different emission levels of pheromone and parapheromone [21]. The present study indicated that $0.1 \mathrm{~mL}$ of the extracted essential oil per trap would provide similar results which are observed in same amount of commercial methyl eugenol. Results of the fruit fly attraction is in agreement with Ravikumar (year), who investigated the fruit fly trapping systems by using methyl eugenol and protein food baits in guava and mango orchards [22].

Table 3. Total number of fruit flies attracted to essential oils of Ocimum tenuiflorum $\mathbf{M T}_{1}$ and $\mathrm{MT}_{2}$ and positive control (n=5); (Mean values to the nearest whole number)

\begin{tabular}{|c|c|c|c|}
\hline \multirow{2}{*}{ Time } & \multicolumn{3}{|c|}{ Number of fruit flies (mean \pm SE) attracted to } \\
\cline { 2 - 4 } & $\begin{array}{c}\text { Essential oil of } \\
\mathrm{MT}_{1}\end{array}$ & $\begin{array}{c}\text { Essential oil of } \\
\mathrm{MT}_{2}\end{array}$ & $\begin{array}{c}\text { Positive control } \\
(\mathrm{ME})\end{array}$ \\
\hline 1st week & $106 \pm 8.1^{\mathrm{a}}$ & $104 \pm 2^{\mathrm{a}}$ & $111 \pm 8.5^{\mathrm{a}}$ \\
\hline 2nd week & $93 \pm 4.1^{\mathrm{ab}}$ & $84 \pm 4.5^{\mathrm{b}}$ & $99 \pm 6.2^{\mathrm{a}}$ \\
\hline 3rd week & $76 \pm 3.0^{\mathrm{a}}$ & $65 \pm 5.2^{\mathrm{ab}}$ & $53 \pm 9.2^{\mathrm{b}}$ \\
\hline 4th week & $48 \pm 6.0^{\mathrm{a}}$ & $38 \pm 2.0^{\mathrm{ab}}$ & $37 \pm 3.0^{\mathrm{b}}$ \\
\hline
\end{tabular}

Means followed by the same letter are significantly different at $\mathrm{P}=0.05$. ME - Methyl Eugenol

\section{Conclusion}

Results clearly demonstrated two morphotypes of $O$. tenuiflorum with high methyl eugenol content for the first time in Sri Lanka. The essential oil extracted from two morphotypes of $O$. tenuiflorum, exhibited similar fruit fly attraction ability as purified methyl eugenol. Therefore, these two morphotypes could be used as initial materials for the large scale cultivation of $O$. tenuiflorum for commercial extraction of oils and to develop an essential oil based paraphermone in order to control the fruit fly menace in Sri Lanka as well as globally.

\section{Conflict of Interest}

Authors declare that there is no conflict of interest.

\section{Acknowledgement}

Authors wish to acknowledge National Research Council for financial support (PPP/12/26)

\section{References}

[1] Hui, Y., Jianhong, L., Population dynamics of oriental fruit fly Bactrocera dorsalis (Diptera: Tephritidae) in Xishuangbanna, Yunnan Province, China. Frontiers of Agriculture in China. 1, 7680. 2007.

[2] Ronald, J., Prokopy Neil W., Miller Jaime, C., Piñero James, D., Barry Linda, C., Tran Leslie Oride and Roger I. Vargas., Effectiveness of GF-120 fruit fly bait spray applied to border area plants for control of melon flies (Diptera: Tephritidae). Journal of Economic Entomology. 96 (5), 1485-1493. 2003.

[3] Dashad, S.S., Chaudhary, O.P., Rakesh., Chemical control of fruit fly. Crops Res. Hisar., 17, 333-335. 1999.

[4] Makhmoor, H. D., and Singh, S.T., Effect of cultural operations of pupal mortality and adult emergence of guava fruit fly Daucus dorsalis Handel. Ann.Pl. Prot. Sci. 7, 33-36. 1999.

[5] Saikia, D.K., and Dutta, S.K., Efficacy of some insecticides and plant products against fruit fly, Daucus tau (Walker) on ridge gourd, Luffa acutangula LJ. Agrie. Sci. Soc. North-East India 10, 132-135. 1997.

[6] Purnima, S., Saxena, S.K. and Sinha, P., Effect of culture filtrates of three fungi, in different combinations, on the development of 
the fruit fly, Dacus Cucurbitae Coq. Ann. PI. Prot. Sci. 7, 96-99. 1999.

[7] Tandon, P.L., Lal, B., Control of mango mealybug Drosicha mangiferae Green by application of insecticides in soil. Entomol. 5, 67-69. 1980.

[8] Yousuf, M., Ashraf, M., Effect of some organophosphates on major insect pests of mango by stem injection. Pakistan Entomol. 9, 9-12. 1987.

[9] Iwahashi, O., Syamusdin-Subahar, T.S., Sastrodihardjo, S., 1996. Attractiveness of Methyl Eugenol to the fruit fly Bactrocera carambolae (Diptera: Tephritidae) in Indonesia. Annals of the Entomological Society of America. 89 (5), 653-660. 1996.

[10] Steiner, L.F., Larches, L., A test of male annihilation method for oriental fruit fly control. J. Econ. Ent. 48, 311-7. 1955.

[11] Steiner, L.E., Mitchell, W.C., Harris, E.J., Kozuma, T.T. and Fujimoto, M.S., Oriental fruit fly eradication by male annihilation. J. Econ. Ent. 58, 961-4. 1965.

[12] Ushio, S.K., Yoshika Nakasu, K., Waki, K., Eradication of oriental fruit fly from Amami Island by male annihilation. Japinees. J. Appl. Ent. Zool. 26, 1-9. 1982.

[13] Alyokhin, A.V., Messing, R.H., Duan, J.J., Visual and olfactory stimuli and fruit maturity affect trap captures of oriental fruit flies (Diptera: Tephritidae). J. Econ. Entomol., 93, 644-649. 2000.

[14] Marwat, N.K., Baloch, U.K., Research note. Methyl eugenol a male fruit fly sex attractant. Pak. J. Agri. Res. 7, 234. 1986.

[15] Bunarathep, S., Palanuvej, C., Ruangrungsi, N., Chemical compositions and antioxidative activities of essential oils from
Ocimum species endemic to Thailand. J. Health Res. 21 (3), 210 206. 2007.

[16] Laskar, S., Majumdar, S. G., Variation of major constituents of essential oil of the leaves of Ocimum sanctum L. J. Indian Chem. Soc. 65, 301-302. 1988.

[17] Kothari, S.K,, Bhattacharya, A. K., Essential oil yield and quality of methyl eugenol rich Ocimum tenuiflorum L.f. (syn. O. sanctum L.) grown in south India as influenced by method of harvest. J. Chrom. A. 1054 (1-2), 67-72. 2004.

[18] Roger, I. Vargas, Todd E. Shelly, Luc Leblanc, Jaime C. Piñero. Chapter Twenty-Three-Recent Advances in Methyl Eugenol and Cue-Lure Technologies for Fruit Fly Detection, Monitoring, and Control in Hawaii. Vitamins \& Hormones. 83, 575-595. 2010.

[19] Wee, S.L., Hee, A.K.W., Tan, K.H., Comparative sensitivity to and consumption of methyl eugenol in three Bactrocera dorsalis (Diptera: Tephritidae) complex sibling species. Chemoecology 12, 193-197. 2002.

[20] Chuah, C.H., Yong, H.S., Goht, S.H., Methyl eugenol, a fruit-fly attractant, from the browning leaves of Proiphys amboinensis (Amaryllidaceae). Biochemical Systematics and Ecology, 25, 391393. 1997.

[21] Llopis, N.V., Alfaro, C., Primo, J., Vacas, S., Response of two tephritid species, Bactrocera oleae and Ceratitis capitata, to different emission levels of pheromone and parapheromone. Crop Protection. 30, 913-918. 2011.

[22] Ravikumar, P., 2006. Studies on fruit fly trapping systems by using methyl eugenol and protein food baits in guava and mango orchards. MSc Thesis, Dharwad: University of Agricultural Sciences. 